Article

\title{
Dynamic Pollution Prediction Model of Insulators Based on Atmospheric Environmental Parameters
}

\author{
Siyi Chen * and Zhijin Zhang \\ State Key Laboratory of Power Transmission Equipment \& System Security and New Technology, \\ Chongqing University, Chongqing 400044, China; zhangzhijing@cqu.edu.cn \\ * Correspondence: 20163155@cqu.edu.cn; Tel.: +86-152-2300-5117
}

Received: 8 May 2020; Accepted: 12 June 2020; Published: 13 June 2020

\begin{abstract}
Pollution-induced flashover is one of the most serious power accidents, and the pollution degree of insulators depends on atmospheric environmental parameters. The pollution models used in the power system research are usually static, but the environmental parameters are dynamic. Therefore, the study on the dynamic pollution prediction model is of great importance. In this paper, the dynamic pollution prediction model of insulators based on atmospheric environmental parameters was built, and insulators' structure coefficients were proposed based on the model. Firstly, the insulator dynamic pollution model based on meteorological data (PM2.5, PM10, TSP (total suspended particulate), and wind speed) was proposed, and natural pollution tests were also conducted as verification tests. Furthermore, insulator structure coefficients $c 1, c 2$ ( $c 1$ : pollution ratio of U210BP/170 to XP-160; c2: calculated pollution ratio of U210BP/170T to XP-160) were then obtained, and their influence factors were discussed. At last, insulator structure coefficients were calculated, and it can be seen that the calculated error of insulator structure coefficients was acceptable, with the average $r e$ (relative errors) at $9.0 \%(c 1)$ and $13.5 \%(c 2)$, which verifies the feasibility of the model. Based on the results in this paper, the NSDD (non-soluble deposit density) of insulators with different structures can be obtained using the insulators' structure coefficient and the reference XP-160 insulator's NSDD.
\end{abstract}

Keywords: dynamic pollution model; reference insulators; insulator structure coefficient; natural pollution tests; finite element method

\section{Introduction}

Pollution-induced flashover is among the most serious power accidents, which seriously threatens the safety and stability of the power system [1-5]. In the past three decades, China has suffered from air pollution due to rapid economic growth, industry-led urbanization, and a lack of environmental protection [6]. Severe air pollution aggravates the possibility of pollution flashover [7]. Therefore, much literature has focused on the issue of insulator contamination [8-21].

It will cost a lot of workforces and material resources to test the pollution degree of insulators operating in transmission lines. Therefore, some scholars have first studied insulator contamination in a wind tunnel and other pollution accumulation systems [8-12]. For example, insulator contamination characteristics were studied by wind tunnel simulation in the literature [8], and the results suggest that insulator structures, wind speed and RH (relative humidity) have obvious impacts on the contamination degree of insulators. Research on the contamination characteristics in the winter environment $[9,10]$ also show that the wind speed has a greater effect on insulator contamination and NSDD. Y. Liu et al. [11] set up a natural pollution accumulation system and uses it to analyze the contamination characteristics and the micro-shape features of the insulator surface. The results show that the DC electric field has a significant effect on agglomeration characteristics. 
In addition, the analysis methods based on finite element, grey theory, etc. are also applied to the insulator pollution model [13-18]. For example, the coupling physics model of a three-unit $\mathrm{XP}-160$ insulator string was established in the literature [13]. Moreover, the contamination deposition process was simulated using the multiphysics simulation software Comsol. Based on the grey theory, X. Qiao et al. [14] established the insulator pollution model, but the result shows that there are still some errors. The error is the error between the calculated ESDD (equivalent salt deposit density) and the actual ESDD. The error mainly comes from the defect of the algorithm and the calculation accuracy fluctuates with the sample selection. Z. Zhang et al. [15] presented the contamination results using a volume fraction which was obtained by a Eulerian two-phase flow model and further proved the feasibility of this method. What is more, little literature has studied insulator contamination in the natural environment [19-21]. However, Z. Zhang et al. [19] pointed out that it will take long time and high expense to get reliable results.

In addition, the pollution model used in the power system is usually static, but the environmental parameters are dynamic. There is less study on the quantitative relationship between the pollution degree and the dynamic environmental parameters. Moreover, now in the power system, the actual insulator's NSDD (non-soluble deposit density) is usually determined by measuring the reference XP-160 insulator's NSDD. However, even in the same pollution condition, the pollution levels of insulators with different structures are various.

Therefore, the dynamic pollution prediction model of insulators based on atmospheric environmental parameters was built, and insulator structure coefficients were proposed based on the model in this paper.

\section{Dynamic Pollution Prediction Model of Insulators}

\subsection{Numerical Simulation Based on Eulerian Two-Phase Model}

The practicability of the method based on the Eulerian two-phase model in engineering has been verified in the literature [15,22-24]. In the Eulerian simulation model, the different phases are treated mathematically as interpenetrating continua. In the simulation model, the standard k- $\varepsilon$ model is used to describe the effects of turbulent fluctuations of velocities. The basic equations of the k- $\varepsilon$ model have been given in our previous research [15]. Ti (turbulence intensity) can be calculated according to Re (Reynolds number). More specifically, $\mathrm{Ti}=0.16 \mathrm{Re}^{-1 / 8}$.

In this paper, seven-unit 3D insulator string models are established by the Solidworks. The insulators' structure and structural parameters are shown in Table 1. The seven-unit 3D insulator string models are imported into Ansys, and a wind tunnel computational domain $(9 \mathrm{~m} \times 2.5 \mathrm{~m} \times 7 \mathrm{~m})$ is created according to the studies $[13,25,26]$, as is shown in Figure 1a. One side of the computational domain is the air and particles inlet, and the other side is the flow outlet.

Table 1. Profile parameters of insulators.

\begin{tabular}{cccccc}
\hline \multirow{2}{*}{ Samples } & \multicolumn{3}{c}{ Parameters } & & Structure \\
\cline { 2 - 3 } & $H(\mathbf{m m})$ & $D(\mathbf{m m})$ & $L(\mathbf{m m})$ & & \\
$\mathrm{U} 210 \mathrm{BP} / 170$ & 155 & 300 & 450 & & \\
\hline
\end{tabular}


Table 1. Cont.

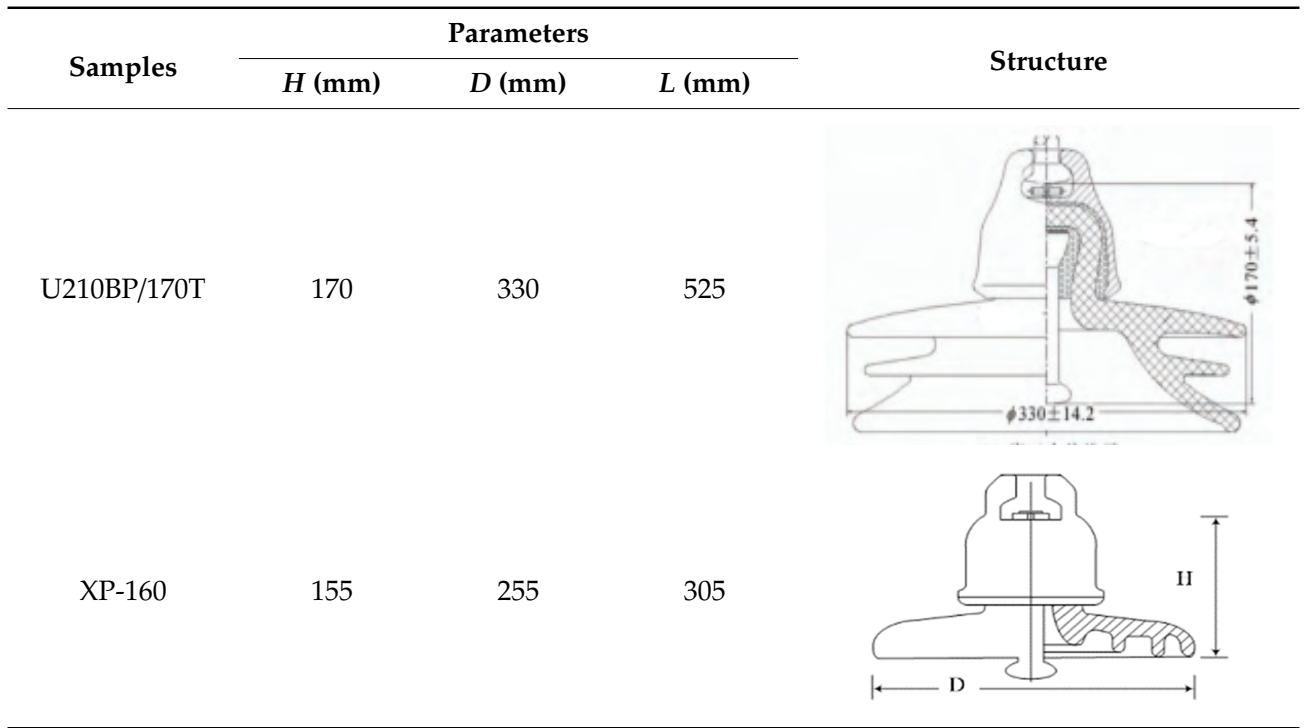

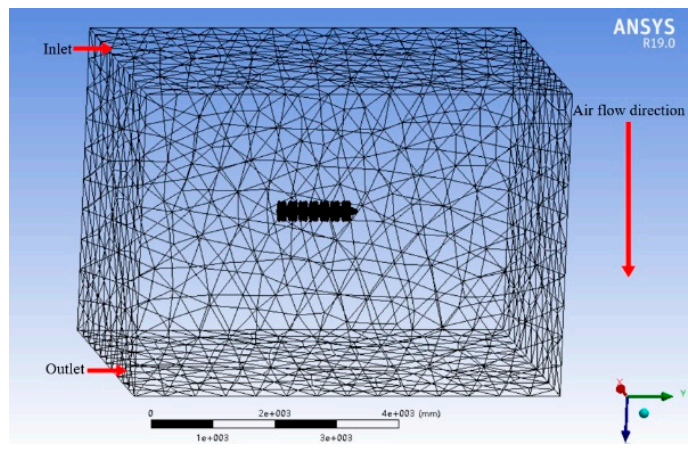

(a)

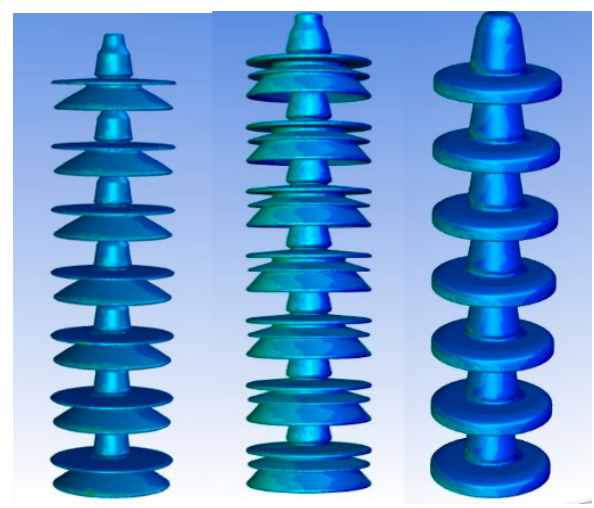

(b)

Figure 1. Calculation model and simulation results: (a) the calculation model in Ansys; (b) the simulation results of $\mathrm{U} 210 \mathrm{BP} / 170, \mathrm{U} 210 \mathrm{BP} / 170$ and $\mathrm{XP}-160$.

Furthermore, a size function is attached to the four regions around the insulator to control the size of the grid cells, and these regions mesh with tetrahedral cells. The outer regions are meshed with hexahedron and prism cells to reduce the number of grids. Practical experience shows [15] that this grid meshing technique improves the calculation accuracy and reduces the cost of calculation time. Then, the boundary condition setting of the calculation domain is processed. The inlet of the 
domain is set to the "velocity-inlet" boundary type, and the outlet of the domain is set to the "out-flow" boundary type.

The calculated results in this paper are shown in Figure $1 \mathrm{~b}$. When the initial concentration settings are the same (0.06), the pollution performance of the insulator was mainly affected by the particle diameter and wind speeds. Specifically, when the initial concentration is 0.06 , the simulation results relationship between the volume fraction of the three insulators and the different particle diameters and different wind speeds are shown in Figure 2. It can be seen that the wind speed $\left(W_{i}\right)$ and particle size $\left(d_{p}\right)$ have a great influence on the pollution performance, but the influence on each insulator are not the same. Besides, the Euler two-phase flow simulation led to steady-state results; therefore, it is necessary to establish a connection between the simulated accumulation results and the actual accumulated pollution results. Thus, the simulation results with the same environmental parameters are compared with the wind tunnel experiments. Finally, the NSDDs of each insulator string are obtained by simulation and comparison.

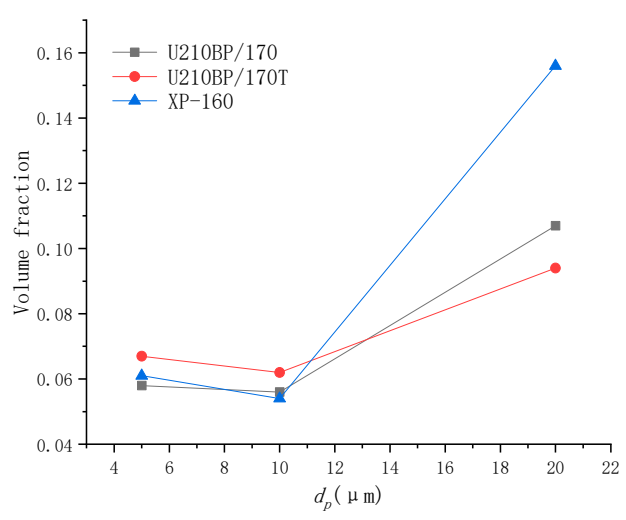

(a) $W_{i}=6 \mathrm{~m} / \mathrm{s}$

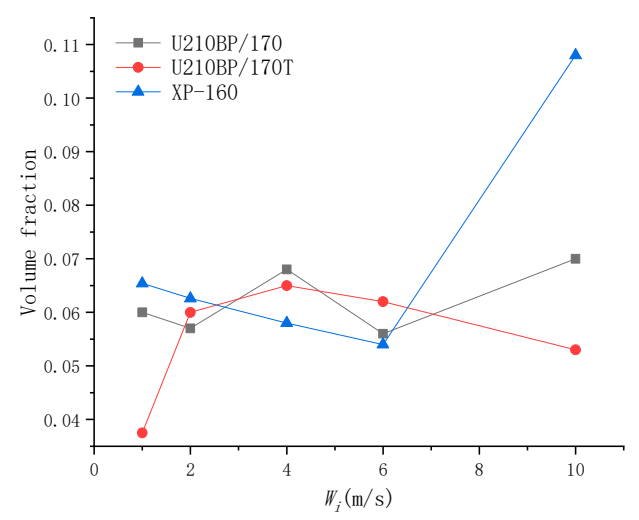

(b) $d_{p}=10 \mu \mathrm{m}$

Figure 2. Simulation results: (a) the volume fraction with a different particle diameter; and (b) the volume fraction with a different wind speed.

\subsection{Dynamic XP-160 Pollution Model Based on Meteorological Data}

The pollution accumulation degree depends on meteorological conditions. For example, the number of pollution particles adhered to the surface of insulator increases with the increase in pollution concentration. According to the corresponding meteorological data, the pollution amount of the insulator surface area under the condition of the pollution concentration can be obtained. In consideration of the time-varying dynamic change of atmospheric environmental parameters, the pollution amount of insulator surface area should be superposed by the accumulated pollution amount of each period, namely:

$$
\begin{gathered}
\Delta \phi_{m i}=\int_{0}^{d_{p M}} \frac{c_{p i}\left(d_{p}\right)}{c_{p 0}} \cdot t_{i} \cdot \rho_{m}\left(V_{i}, d_{p}\right) d d_{p} \\
\phi_{m}(H)=\sum_{i=1}^{N} \Delta \phi_{m i}, H=\sum_{i=1}^{N} t_{i}
\end{gathered}
$$

where, $c_{p 0}$ is the reference concentration, $15 \mathrm{mg} / \mathrm{m}^{3} \cdot c_{p i}\left(d_{p}\right)$ is the concentration corresponding to the polluted particles with the particle size of $d_{p}$ in the $i$ time period, $\mathrm{mg} / \mathrm{m}^{3} . V_{i}$ is the wind speed in this time period, $\mathrm{m} / \mathrm{s} ; t_{i}$ is the time length in the $i$ time period. $\rho_{m}\left(V_{i}, d_{p}\right)$ is the pollution accumulation per unit time on the insulator surface. $d_{p M}$ is the maximum particle size of the atmospheric particles in the $i$ time period, $\mu \mathrm{m} . \Delta \Phi_{m i}$ is the pollution increment of the insulator surface area in the $i$ time period, $\mathrm{mg} / \mathrm{cm}^{2} . H$ is the total time in each time period. $\Phi_{m}(H)$ is the final accumulated pollution amount of the polluted particles on the insulator surface, $\mathrm{mg} / \mathrm{cm}^{2}$. 
The $c_{p i}\left(d_{p}\right)$ cannot be directly measured, but it needs to be obtained through the relationship between the particle size and its mass concentration, but the relationship is difficult to measure and obtain. Therefore, the approximate method is adopted, and it is considered that the mass fraction and particle size of the polluted particles meet the rosin rammer distribution:

$$
\lambda_{i}\left(d_{p}\right)=1-\exp \left(-n_{2} \cdot d_{p}{ }^{n_{1}}\right)
$$

where $\lambda_{i}\left(d_{p}\right)$ is the mass fraction of the polluted particles, whose particle size is less than $d_{p}$ in the $i$ time period. $n_{1}$ is the distribution characteristic index. $n_{2}$ is the distribution characteristic coefficient.

The meteorological department usually classifies the polluted particles according to the air quality index standard of real-time monitoring: PM2.5 $\left(d_{p}<2.5 \mu \mathrm{m}\right)$, PM10 $\left(d_{p}<10 \mu \mathrm{m}\right)$, TSP (total suspended particulate) $\left(d_{p}<100 \mu \mathrm{m}\right)$. The units of these three parameters are $\mu \mathrm{g} / \mathrm{m}^{3}$. According to the data measured in the $i$ time period, the PM2.5, PM10 and TSP can be obtained:

$$
\begin{aligned}
& \text { PM2.5/TSP }=1-\exp \left(-n_{2} \cdot 2.5^{n_{1}}\right) \\
& \text { PM10/TSP }=1-\exp \left(-n_{2} \cdot 10^{n_{1}}\right) \\
& 1=1-\exp \left(-n_{2} \cdot 100^{n_{1}}\right)
\end{aligned}
$$

By fitting Equation (3), $n_{1}, n_{2}$ can be obtained, and then the mass fraction particle size distribution function of the $i$ time period can be obtained. Taking the air pollution monitoring data of an area as an example, the TSP, PM10 and PM2.5 measured in the period $i$ are about $200 \mu \mathrm{g} / \mathrm{m}^{3}, 120 \mu \mathrm{g} / \mathrm{m}^{3}, 24 \mu \mathrm{g} / \mathrm{m}^{3}$, then the values of $n_{1}, n_{2}$ are 1.42 and 0.03 , respectively:

$$
\lambda_{i}\left(d_{p}\right)=1-\exp \left(-0.03 \cdot d_{p}^{1.42}\right)
$$

The fitting degree $R^{2}$ is 0.99 , which shows that the fitting result is reasonable. After the mass fraction-particle size relationship is obtained, Equation (2) can be discretized to approximate the mass fraction size corresponding to each particle size, and then the concentration $c_{p i}\left(d_{p}\right)$ can be obtained:

$$
c_{p i}\left(d_{p}\right) \approx \mathrm{TSP} \cdot\left[\lambda\left(d_{p}\right)-\lambda\left(d_{p}-\Delta d_{p}\right)\right]
$$

In order to improve the calculation efficiency and take into account the accuracy, setting $\Delta d_{p}$ as $1 \mu \mathrm{m}$. In general, the probability of an air pollution particle size less than $50 \mu \mathrm{m}$ is $99 \%$. Therefore, only the influence of a pollution particle size less than $50 \mu \mathrm{m}$ needs to be considered in the prediction of pollution accumulation. Based on the discretization of Equation (5), the following results are obtained:

$$
\begin{aligned}
& c_{p i}(1)=\mathrm{TSP} \cdot\left[1-\exp \left(-n_{2} \cdot 1^{n_{1}}\right)\right] \\
& c_{p i}(2)=\mathrm{TSP} \cdot\left[-\exp \left(-n_{2} \cdot 2^{n_{1}}\right)+\exp \left(-n_{2} \cdot 1^{n_{1}}\right)\right] \\
& \cdots \\
& c_{p i}(50)=\mathrm{TSP} \cdot\left[-\exp \left(-n_{2} \cdot 50^{n_{1}}\right)+\exp \left(-n_{2} \cdot 49^{n_{1}}\right)\right]
\end{aligned}
$$

Taking the particle mass fraction-particle size distribution function obtained in Equation (4) as an example, and using the method of Equation (6) to discretize, the pollution particle concentration $c_{p i}\left(d_{p}\right)$ corresponding to each $d_{p}$ value can be obtained, as shown in Figure 3:

Taking Equation (6) into Equation (1) to get the final amount of air pollution particles on the insulator surface after $H$ time of pollution accumulation:

$$
\phi_{m}(H)=\sum_{i=1}^{N} \Delta \phi_{m i}=\sum_{i=1}^{N}\left(\sum_{n=1}^{50} \frac{c_{p i}\left(d_{p}\right)}{c_{p 0}} \cdot t_{i} \cdot \rho_{m}\left(V_{i}, d_{p}\right)\right)
$$

As mentioned before, $\rho_{m}\left(V_{i}, d_{p}\right)$ is the pollution accumulation per unit time on the insulator surface, which can be obtained through several ways, such as the numerical simulation of pollution deposition, 
wind tunnel tests and nature tests. Furthermore, the pollution degree and insulator structure pollution coefficients (the coefficients will be discussed in the discussion section) can be calculated according to the flow chart based on the proposed model in this paper, as is shown in Figure 4:

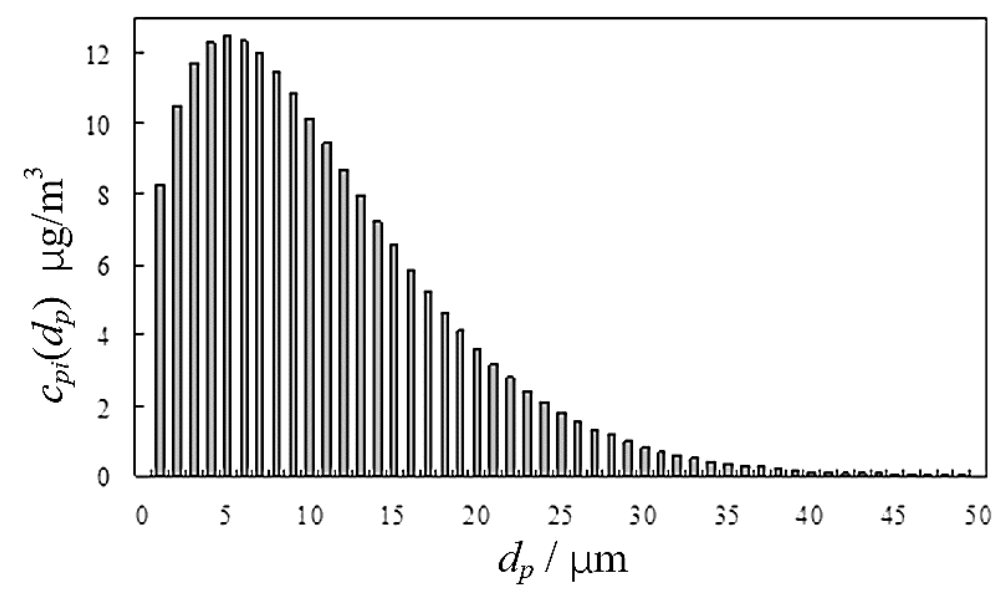

Figure 3. An example of the calculation result of the particle concentration-diameter relationship.

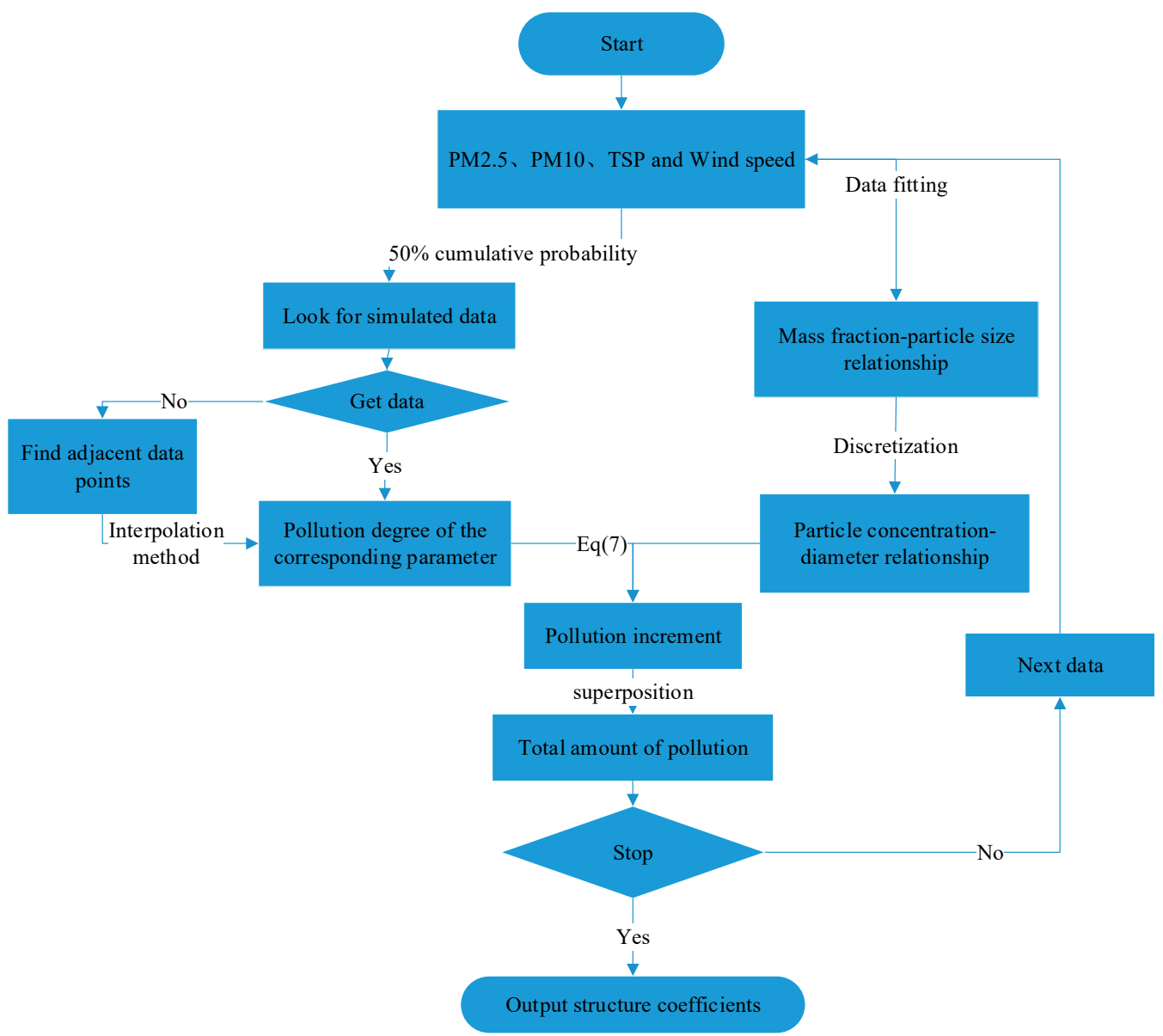

Figure 4. Flow chart of the pollution degree and the coefficients calculation. 


\subsection{Model Validation}

\subsubsection{The Experiment Procedures}

The contamination samples were three types of insulators arranged in different towers. The test samples arrangement are shown in Figure 5. Firstly, seven units of three types of insulator strings (U210BP/170, U210BP/170T and XP-160) were suspended in the test towers. When the tests were completed, the samples were carefully taken out of the towers. The measuring method of contamination in our previous research [8] is shown in Figure 6. The measuring process is referred to as the IEC Standard 60,507 [8]. It should be noted that the experimental results were the average values of insulator pieces results. When one experiment ended, the next experiment cycle continued.

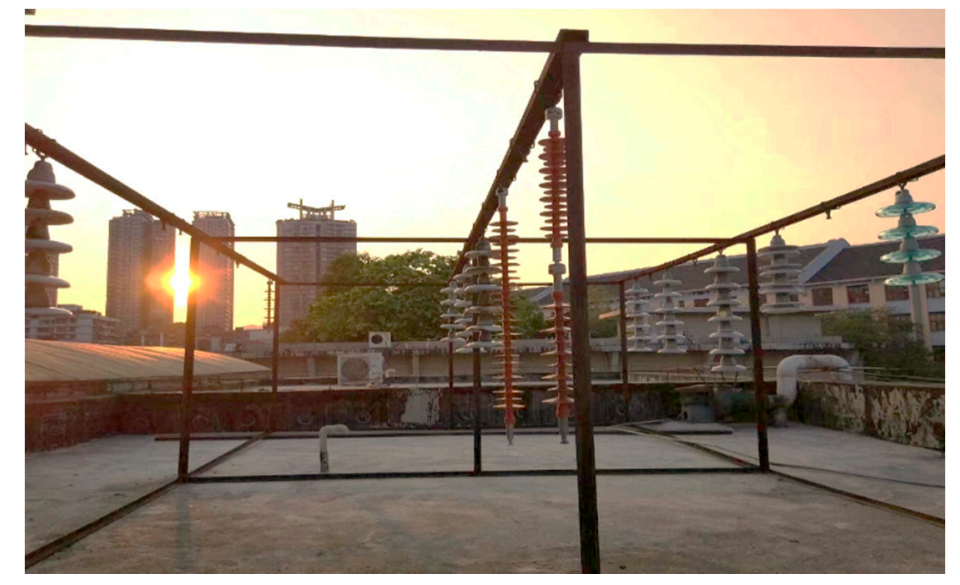

Figure 5. Field pollution tests.

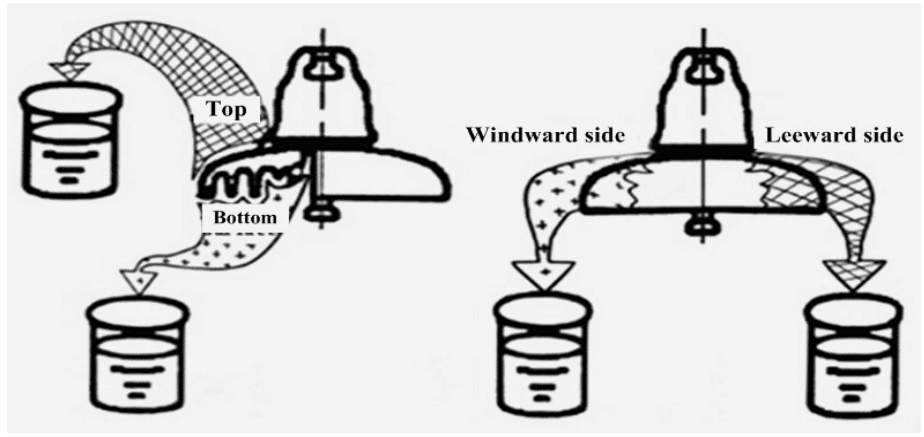

(a)

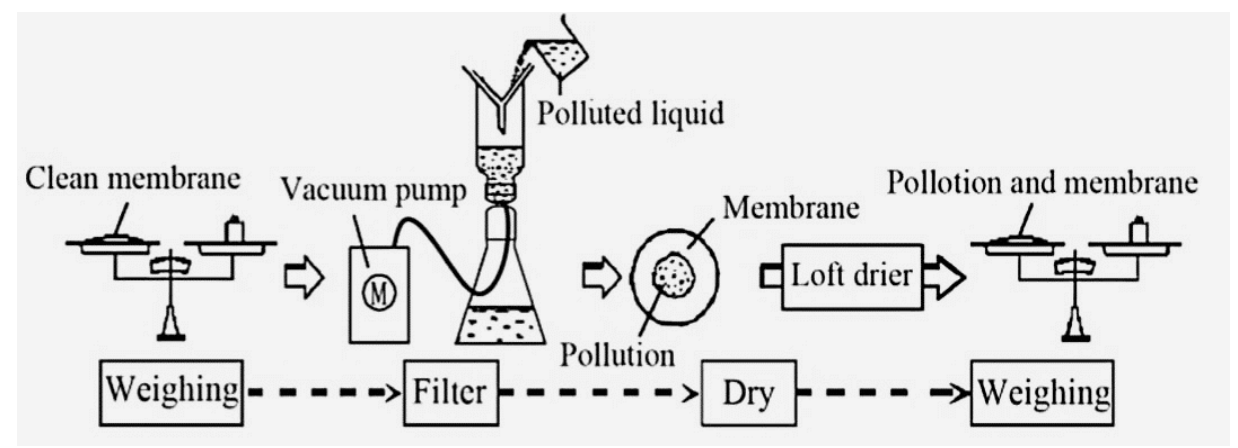

(b)

Figure 6. The measuring method of contamination [8]: (a) the collection of contamination; and (b) the contamination weighing process. 


\subsubsection{The Experiment Results and Calculated re}

The experimental results are shown in Table 2 (corresponding meteorological parameters of the first period are shown in Figure 7). Since the meteorological parameters are constantly changing, it is necessary to process the meteorological data before applying the model calculation. In this paper, $50 \%$ cumulative probability density is used to express the meteorological parameters in the $H$ period. The cumulative probability distribution, also known as the cumulative distribution function, the distribution function and so on, is used to describe the probability of random variables falling on any interval, which is often regarded as the characteristics of the data. If the variable is continuous, the cumulative probability distribution is the function obtained by integrating the probability density function; if the variable is discrete, the cumulative probability distribution is a function obtained by adding the distribution law.

Table 2. Tests result and calculated re.

\begin{tabular}{|c|c|c|c|c|c|c|}
\hline \multirow{2}{*}{$\frac{\text { Samples }}{\left(\times 10^{-3} \mathrm{mg} / \mathrm{cm}^{2}\right)}$} & \multicolumn{2}{|c|}{$\mathrm{U} 210 \mathrm{BP} / 170$} & \multicolumn{2}{|c|}{$\mathrm{U} 210 \mathrm{BP} / 170 \mathrm{~T}$} & \multicolumn{2}{|c|}{ XP-160 } \\
\hline & NSDD & re & NSDD & re & NSDD & re \\
\hline $\mathrm{T} 1$ & 4.3 & $12.6 \%$ & 6.2 & $9.8 \%$ & 9.8 & $13.5 \%$ \\
\hline $\mathrm{T} 2$ & 3.1 & $10.6 \%$ & 3.4 & $11.3 \%$ & 5.6 & $14.0 \%$ \\
\hline T3 & 3.5 & $12.6 \%$ & 4.1 & $12.4 \%$ & 6.5 & $7.5 \%$ \\
\hline $\mathrm{T} 4$ & 2 & $8.5 \%$ & 2.7 & $11.8 \%$ & 4.2 & $10.9 \%$ \\
\hline T5 & 3.5 & $7.5 \%$ & 4.2 & $9.6 \%$ & 7.6 & $7.9 \%$ \\
\hline T6 & 6.8 & $15.9 \%$ & 6.9 & $17.5 \%$ & 10.2 & $14.9 \%$ \\
\hline $\mathrm{T} 7$ & 5.1 & $20.5 \%$ & 5.5 & $18.9 \%$ & 7.3 & $21.5 \%$ \\
\hline
\end{tabular}

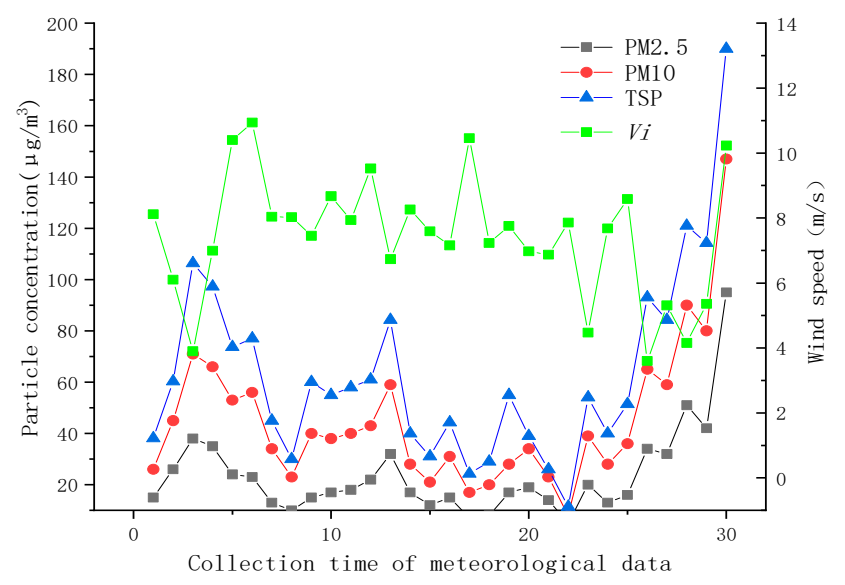

Figure 7. Thirty sets of meteorological data.

According to the results in Table 2, the relative errors between the predicted outcome and the measured results are basically within $20 \%$. Therefore, a new method was proposed to predict insulator contamination by using meteorological monitoring data, which provides a new idea for insulator contamination in a natural environment prediction. At present, the prediction method in this paper can only be used for predicting NSDD. There are complex chemical reactions involved in the ESDD (formation of salt density) and the calculation is more complicated, since ESDD is closely related to the composition of sulfur-containing and nitrogen-containing gases in the atmosphere.

\section{Discussion}

\subsection{Model Error Analysis}

According to the above calculation results, this section further discusses the causes of errors. Figure 8 is obtained from the calculation results. It can be seen from Figure 8 that the error of the 
dynamic pollution model based on atmospheric parameters is different. The re of T1-T5 are relatively small, with its value varying from $7.5 \%$ to $14 \%$. However, the re of T6-T7 are relatively larger, with its value standing at about $20 \%$.

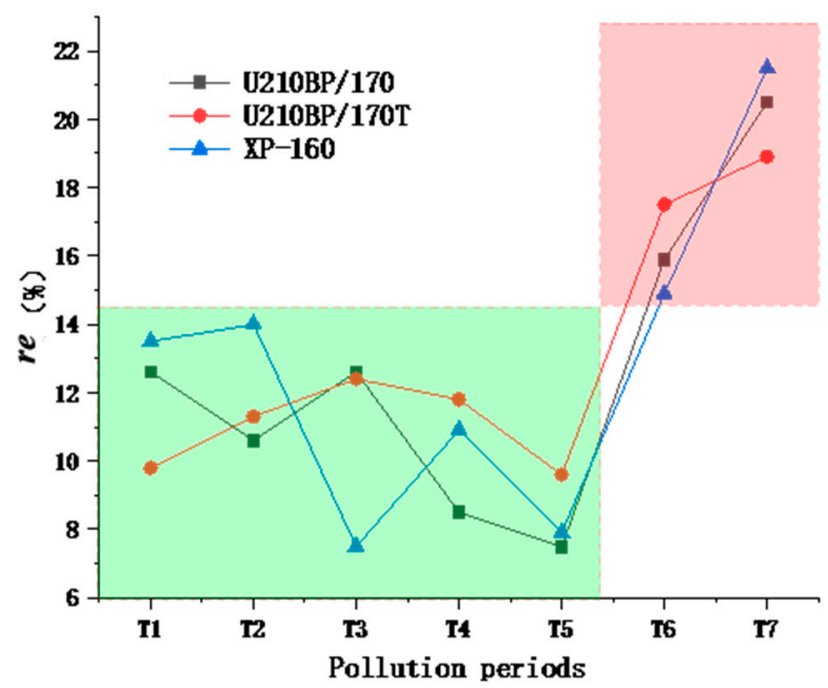

Figure 8. Calculated re.

According to the differences between the different $r e$, the characteristics of meteorological parameters are further investigated. It was found that, there are five days of rainfall in the sixth stage; while in the seventh stage, there are eight days of rainfall, and the rainfalls are heavy. Therefore, it can be concluded that rainfall mainly causes the errors in the dynamic accumulation model [27].

\subsection{Insulator Structure Coefficients}

Now in the power system, the actual insulator's NSDD is usually determined by measuring the NSDD of the reference insulator XP-160. However, even under the same pollution condition, the pollution degrees of insulators with different structures varies. Therefore, insulator structure coefficients $c 1$ and $c 2$ are further calculated. Table 3 and Figure 9 can be obtained.

Table 3. Insulator structure coefficients.

\begin{tabular}{cccccccc}
\hline & T1 & T2 & T3 & T4 & T5 & T6 & T7 \\
\hline$c 1$ & 0.439 & 0.554 & 0.538 & 0.476 & 0.461 & 0.667 & 0.699 \\
$c 2$ & 0.633 & 0.607 & 0.631 & 0.643 & 0.553 & 0.676 & 0.753 \\
\hline
\end{tabular}

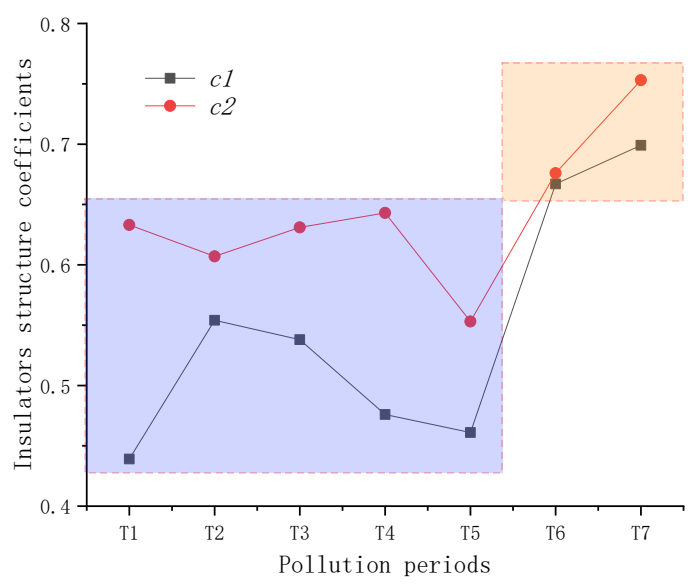

Figure 9. Insulator structure coefficients. 
As shown in Figure 9, the value of $c 1$ ( $c 2$ ) witnessed fluctuation, and the change was evident with its figure varying between 0.439 and 0.699 (0.553 and 0.753). In addition, rainfall had a significant influence on the insulators' structure coefficients, since $c 1$ and $c 2$ increased to a certain extent during the rainfall period. It can be discovered by further calculation that insulator structure coefficient varies due to the change of wind speed, particle size and other factors, with no obvious changing patterns. Hence, this indicates that insulator structure coefficients are dynamic.

Therefore, the original method for obtaining the pollution level of transmission line insulators only by reference insulator is unreasonable. Insulator structure coefficients should be taken into consideration to get the pollution degree. However, it is time consuming and labor consuming to obtain insulator structure coefficients from natural experiments. Therefore, the insulator structure pollution coefficients can be calculated according to the flow chart based on the proposed model in this paper. And the calculated results are show in Table 4:

Table 4. Calculated insulator structure coefficients.

\begin{tabular}{ccccccccc}
\hline & T1 & T2 & T3 & T4 & T5 & T6 & T7 & Average $r$ e \\
\hline$c 1^{\prime}$ & 0.523 & 0.612 & 0.596 & 0.651 & 0.423 & 0.536 & 0.642 & \\
$c 2^{\prime}$ & 0.694 & 0.745 & 0.712 & 0.731 & 0.501 & 0.545 & 0.684 & \\
$r e 1$ & 0.192 & 0.106 & 0.107 & 0.077 & 0.081 & 0.021 & 0.081 & $9.0 \%$ \\
$r e 2$ & 0.097 & 0.227 & 0.129 & 0.137 & 0.093 & 0.125 & 0.092 & $13.5 \%$ \\
\hline
\end{tabular}

It can be seen that the calculated error of insulator structure coefficients is acceptable, with the maximum value at $19.2 \%(r e 1)$ and $22.7 \%$ (re2), and the average value at $9.0 \%(r e 1)$ and $13.5 \%(r e 2)$, which verifies the feasibility of the model.

\section{Conclusions}

In this paper, the dynamic pollution prediction model of insulators based on atmospheric environmental parameters was built, and insulator structure coefficients were proposed based on the model.

Firstly, the insulator dynamic pollution model based on meteorological data (PM2.5, PM10, TSP, and wind speed) was proposed, and natural pollution tests were also conducted as a verification test. Furthermore, insulator structure coefficients $c 1$ and $c 2$ were then obtained, and its influence factors were discussed. Rainfall has a significant influence on the insulator structure coefficient; plus, $c 1$ and $c 2$ increase to a certain extent during the rainfall period. Further calculation of insulator structure coefficients show that it varied with the change of wind speed, particle size and other factors, and there is no obvious changing rule. This result indicates that insulator structure coefficients are dynamic.

At last, insulator structure coefficients $c 1^{\prime}, c 2^{\prime}$ were calculated; besides, it can be seen that the calculated error of insulator structure coefficients is acceptable, with the average $r e$ at $9.0 \%(r e 1)$ and $13.5 \%$ (re2), which verifies the feasibility of the model.

Author Contributions: Methodology, S.C.; Software, S.C.; Data curation, S.C.; Writing-original draft preparation, S.C.; Writing-review and editing, S.C. and Z.Z.; Visualization, S.C.; Supervision, Z.Z. All authors have read and agreed to the published version of the manuscript.

Funding: This research received no external funding.

Acknowledgments: The authors thank all members of external insulation research team (Especially Xinhan Qiao, Dongdong Zhang, Wei Zhang, Jinwei You and others) in Chongqing University for their hard work to obtain the experimental data in this paper.

Conflicts of Interest: The authors declare no conflict of interest. 


\section{References}

1. Sima, W.; Yuan, T.; Yang, Q.; Xu, K.; Sun, C. Effect of non-uniform pollution on the withstand characteristics of extra high voltage (EHV) suspension ceramic insulator string. IET Gener. Transm. Distrib. 2010, 4, 445-455. [CrossRef]

2. Samakosh, J.D.; Mirzaie, M. Investigation and analysis of AC flashover voltage of SiR insulators under longitudinal and fan-Shaped non-Uniform pollutions. Int. J. Electr. Power Energy Syst. 2019, 108, 382-391. [CrossRef]

3. Samakosh, J.D.; Mirzaie, M. Flash-Over voltage prediction of silicone rubber insulators under longitudinal and fan-shaped non-Uniform pollution conditions. Comput. Electr. Eng. 2019, 78, 50-62. [CrossRef]

4. Qiao, X.; Zhang, Z.; Jiang, X.; Sundararajan, R.; Ma, X.; Li, X. AC failure voltage of iced and contaminated composite insulators in different natural environments. Int. J. Electr. Power Energy Syst. 2020, 120, 105993. [CrossRef]

5. Zhang, Z.; Qiao, X.; Zhang, Y.; Tian, L.; Zhang, D.; Jiang, X. AC flashover performance of different shed configurations of composite insulators under fan-shaped non-uniform pollution. IET High Voltage 2018, 3, 199-206. [CrossRef]

6. Zhao, D.; Chen, H.; Li, X.; Ma, X. Air pollution and its influential factors in China's hot spots. J. Clean. Prod. 2018, 185, 619-627. [CrossRef]

7. Ahmadi-veshki, M.; Mirzaie, M.; Sobhani, R. Reliability assessment of aged SiR insulators under humidity and pollution conditions. Int. J. Electr. Power Energy Syst. 2020, 117, 105679. [CrossRef]

8. Qiao, X.; Zhang, Z.; Jiang, X.; Zhang, D. Contamination Characteristics of Typical Transmission Line Insulators by Wind Tunnel Simulation. Electr. Power Syst. Res. 2020, 184, 106288. [CrossRef]

9. Ravelomanantsoa, N.; Farzaneh, M.; Chisholm, W.A. Effects of Wind Velocity on Contamination of HV Insulators in Winter Conditions. In Proceedings of the Annual Report Conference on Electrical Insulation and Dielectric Phenomena, Quebec, QC, Canada, 26-29 October 2008; pp. 240-244.

10. Ravelomanantsoa, N.; Farzaneh, M.; Chisholm, W.A. Simulation method for winter pollution contamination of HV insulators. In Proceedings of the 2011 Electrical Insulation Conference (EIC), Annapolis, MD, USA, 5-8 June 2011; pp. 373-376.

11. Liu, Y.; Wu, G.; Guo, Y.; Zhang, X.; Liu, K.; Kang, Y.; Shi, C. Pollution agglomeration characteristics on insulator and its effect mechanism in DC electric field. Int. J. Electr. Power Energy Syst 2020, 115, 105447. [CrossRef]

12. Gu, C.; Li, J.; Li, M.; Leizhou, Z.; Wei, Z.; Qiaogen, Z.; Zhiyin, Q.; Rong, X.; Chenzhao, F. Study on contamination deposition characteristics of transmission line insulators. In Proceedings of the IEEE 2011 Asia-Pacific Power and Energy Engineering Conference (APPEEC), Wuhan, China, 25-28 March 2011; pp. 1-4.

13. Zhang, D.; Zhang, Z.; Jiang, X.; Shu, L.; Wu, B. Simulation Study on the Effects of DC Electric Field on Insulator Surface Pollution Deposit. Energies 2018, 11, 626. [CrossRef]

14. Qiao, X.; Zhang, Z.; Jiang, X.; Yushen, H.; Xun, L. Application of grey theory in pollution prediction on insulator surface in power systems. Eng. Fail. Anal. 2019, 106, 104153. [CrossRef]

15. Zhang, Z.; Zhang, W.; You, J.; Wu, B.; Maoqiang, B.; Xingliang, J.; Jian, W.; Wei, Z. Influence factors in contamination process of XP-160 insulators based on computational fluid mechanics. IET Gener. Transm. Distrib. 2016, 10, 4140-4148. [CrossRef]

16. Lv, Y.; Li, J.; Zhan, X.; Pang, G. A simulation study on pollution accumulation characteristics of XP13-160 porcelain suspension disc insulator. IEEE Trans. Dielectr. Electric Insul. 2016, 23, 2196-2206. [CrossRef]

17. Wu, X.; Zhang, X.; Wu, G. Simulation and Analysis of Contamination Depositing Characteristic of Roof Insulator. In Proceedings of the 2016 IEEE International Conference on High Voltage Engineering and Application (ICHVE), Chengdu, China, 19-22 September 2016; pp. 1-4.

18. Gu, C.; Li, J.; Zhang, L.; Li, M.; Xiao, R.; Qian, Z. Experimental and numerical study of the pollution accumulation on outdoor insulators. High Volt. Eng. 2011, 11, 2822-2829.

19. Zhang, Z.; Qiao, X.; Yang, S.; Jiang, X. Non-Uniform Distribution of Contamination on Composite Insulators in HVDC Transmission Lines. Appl. Sci. 2018, 8, 1962. [CrossRef]

20. Zhang, Z.; Zhang, D.; Jiang, X.; Liu, X. Study on natural contamination performance of typical types of insulators. IEEE Trans. Dielectr. Electr. Insul. 2014, 21, 1901-1909. [CrossRef] 
21. Chao, Y.; Huang, F.; Zhao, S.; Wang, C.; Wang, F.; Yue, Y. Study on natural pollution accumulating characteristics of cap and pin suspension ceramic insulator with composite shed of DC $500 \mathrm{kV}$ transmission line in central China. In Proceedings of the 2016 IEEE International Conference on High Voltage Engineering and Application (ICHVE), Chengdu, China, 19-22 September 2016; pp. 1-4.

22. Fu, P.; Farzaneh, M. A CFD approach for modeling the rime-ice accretion process on a horizontal-axis wind turbine. J. Wind Eng. Ind. Aerodyn. 2010, 98, 181-188. [CrossRef]

23. Drew, D.A.; Lahey, R.T. In Particulate Two-Phase Flow; Butterworth-Heinemann: Boston, MA, USA, 1993; pp. 509-566.

24. Launder, B.E.; Spalding, D.B. Lectures in Mathematical Models of Turbulence; Academic Press: London, UK, 1972.

25. Xiaohuan, L. Study on the Pollution Accumulation and AC Pollution Flashover Performance of Insulators with Typical Sheds. Master's Thesis, Chongqing University, Chongqing, China, 2013.

26. Haibo, L. Hydrodynamics-Based Contamination Depositing Characteristics Research of Suspension Insulator String. Masters's Thesis, Chongqing University, Chongqing, China, 2010.

27. Jiang, Z.; Jiang, X.; Zhang, Z.; Guo, Y.; Li, Y. Investigating the Effect of Rainfall Parameters on the Self-Cleaning of Polluted Suspension Insulators: Insight from Southern China. Energies 2017, 10, 601. [CrossRef]

(C) 2020 by the authors. Licensee MDPI, Basel, Switzerland. This article is an open access article distributed under the terms and conditions of the Creative Commons Attribution (CC BY) license (http://creativecommons.org/licenses/by/4.0/). 